Article

www.mdpi.com/journal/toxins

\title{
Characterization of SNARE Cleavage Products Generated by Formulated Botulinum Neurotoxin Type-A Drug Products
}

\section{Terrence Hunt*, David Rupp, Gary Shimizu, Karen Tam, Julia Weidler and Jack Xie}

Allergan, Inc., 2525 Dupont Dr, Irvine, CA 92612, USA; E-Mails: rupp_david@allergan.com (D.R.); shimizu_gary@allergan.com (G.S.); tamkaren@gmail.com (K.T.); weidler_julia@allergan.com (J.W.); xie_jack@allergan.com (J.X.)

* Author to whom correspondence should be addressed; E-Mail: hunt_terrence@allergan.com; Tel.: +1-714-246-6268; Fax: +1-714-246-5883.

Received: 9 July 2010; in revised form: 10 July 2010 / Accepted: 18 August 2010 /

Published: 19 August 2010

\begin{abstract}
The study evaluated substrate cleavage product(s) generated by three botulinum neurotoxin serotype A (BoNT/A) medicinal drug products utilizing a novel and highly specific, light-chain activity, high-performance liquid chromatography (LCA-HPLC) method. Samples were reacted with a commercially available BoNT/A fluorescent substrate derived from the SNAP-25 sequence. Reaction products were separated by reversed-phase HPLC. The method detected an atypical cleavage pattern by one of the formulated drug products. IncobotulinumtoxinA produced two cleavage fragments rather than the single fragment typically generated by BoNT/A. Identification confirmed the secondary cleavage at a position corresponding to SNAP-25 Arg198-Ala199 (normal BoNT/A cleavage is Gln197-Arg198). Arg198-Ala199 is also the cleavage site for trypsin and serotype $\mathrm{C}$ toxin. Normal cleavage was observed for all other BoNT/A drug product samples, as well as $900-\mathrm{kD}$ and $150-\mathrm{kD}$ bulk toxin BoNT/A. The reason for this unexpected secondary cleavage pattern by one formulated BoNT/A drug product is unknown. Possible explanations include a contaminating protease and/or damage to the $150-\mathrm{kD}$ type-A toxin causing nonspecific substrate recognition and subsequent cleavage uncharacteristic of type-A toxin. The BoNT/A drug products were also analyzed via the LCA-HPLC assay using a commercial BoNT/C fluorescent substrate derived from the syntaxin sequence. Cleavage of the serotype $\mathrm{C}$ substrate by incobotulinumtoxinA was also confirmed whilst neither of the other drug products cleaved the syntaxin substrate.
\end{abstract}


Keywords: abotulinumtoxinA; botulinum toxin; BOTOX ${ }^{\circledR}$; Dysport ${ }^{\circledR}$; incobotulinumtoxinA; onabotulinumtoxin A; SNAP-25; SNARE; syntaxin; Xeomin ${ }^{\circledR}$

\section{Introduction}

Seven serotypes (A to G) of Clostridium botulinum are known. Each serotype synthesizes a $150-\mathrm{kD}$ neurotoxin (BoNT) along with a group of nontoxic neurotoxin-associated proteins (NAPs) that form complexes [1]. BoNT is a zinc-endopeptidase that is composed of a $100-\mathrm{kD}$ heavy-chain and a $50-\mathrm{kD}$ light-chain, connected by a disulfide bond. The heavy-chain is responsible for binding ( $C$-terminal domain) and translocation ( $N$-terminal domain), whereas the light-chain is responsible for proteolytic activity. The light-chain of each serotype specifically cleaves one or more soluble $N$-ethylmaleimidesensitive factor attachment receptors (SNAREs). The endopeptidase activities of the toxins are unique in that they require the reduction of the disulfide bond between the light and heavy chains in order for enzymatic activity to occur. Each serotype cleaves selectively at a specific peptide bond of a specific substrate. For example, the light-chain of BoNT serotype A (BoNT/A) specifically cleaves SNAP-25 1-206 $^{2}$ at position Gln197-Arg198 [2]. This specific cleavage is an intrinsic property of the serotype.

Serotype $\mathrm{A}$ has been formulated into several drug products for therapeutic treatment of various disorders. The formulated drug products differ considerably in both drug substance and drug product composition (see Table 1).

Table 1. BoNT/A drug product composition.

\begin{tabular}{|c|c|c|c|c|}
\hline $\begin{array}{c}\text { Non-proprietary } \\
\text { Name }\end{array}$ & $\begin{array}{l}\text { Brand } \\
\text { Name } \\
\end{array}$ & $\begin{array}{c}\text { Labeled Potency } \\
\left(\mathrm{LD}_{50}\right)\end{array}$ & Toxin & Excipients \\
\hline onabotulinumtoxin $\mathrm{A}$ & BOTOX $^{\circledR}$ & 100 Units & $\begin{array}{c}\text { BoNT/A } \\
900-\mathrm{kD} \text { complex }\end{array}$ & $\begin{array}{l}0.5 \mathrm{mg} \mathrm{HSA}^{\mathrm{a}} \\
0.9 \mathrm{mg} \mathrm{NaCl}\end{array}$ \\
\hline abotulinumtoxin $\mathrm{A}$ & Dysport $^{\circledR}$ & 500 units & $\begin{array}{c}\text { BoNT/A } \\
300 / 500-\mathrm{kD}^{\mathrm{b}} \text { complex }\end{array}$ & $\begin{array}{l}0.125 \mathrm{mg} \mathrm{HSA}^{\mathrm{a}} \\
2.5 \mathrm{mg} \text { Lactose }\end{array}$ \\
\hline incobotulinumtoxinA & Xeomin $^{\circledR}$ & 100 Units & $\begin{array}{c}\text { BoNT/A } \\
150-\mathrm{kD}\end{array}$ & $\begin{array}{c}1 \mathrm{mg} \mathrm{HSA}^{\mathrm{a}} \\
4.7 \mathrm{mg} \text { Sucrose }\end{array}$ \\
\hline
\end{tabular}

${ }^{\text {a }}$ Human serum albumin.

${ }^{\mathrm{b}}$ Ipsen Biopharm Limited reported molecular weight range of the complex.

Recently the drug products have been assigned non-proprietary (USAN) names to avoid confusion due to brand names and to emphasize the non-interchangeability of units. However, physicochemical evaluations that might offer functional insight into differences have thus far been limited.

It is important to note that it is the SNARE cleavage (described above) that ultimately produces the desired therapeutic effect by inducing regional disruption of neuronal stimulation of an organ (e.g., muscle or sweat gland). Due to the potent nature of the toxin, extremely small therapeutic concentrations are sufficient; typically nanograms per finished drug product vial. The inherent difficulties in analyzing nanogram quantities of formulated drug substance have relegated most comparisons to the clinical setting. However, compared to physicochemical techniques, clinical readouts can be insensitive while providing limited mechanistic information. What has been lacking is 
a highly-sensitive endopeptidase activity assay that is not subject to matrix interference due to excipients and allows simultaneous characterization of cleavage specificity.

Existing endopeptidase assays, such as spectrophotometric assays, are insufficiently sensitive to measure drug product concentrations and are subject to drug product matrix interferences. For example, BoNT/A light-chain activity methods utilizing fluorescence resonance energy transfer (FRET) substrates typically measure a change in fluorescent signal directly from the reaction solution. The total fluorescence of the reaction solution, which includes intrinsic fluorescence due to reaction buffer components and toxin formulation excipients, is measured before and after substrate cleavage. An increase or decrease in fluorescence will result, depending on the FRET pair used. This change in fluorescent signal due to cleavage is non-specific and often small in relation to the background signal, resulting in poor sensitivity. Immunoassays represent another technique employed for measuring endopeptidase activity. These assays rely on the availability of special reagents (i.e., high-affinity antibodies for each cleavage product) to achieve specificity [3] and are incompatible with many commonly used formulation excipients. The result is that most assays currently used are inconvenient, product specific and insensitive, usually requiring many product vials to accomplish a single test that results in only limited information.

The light-chain activity high-performance liquid chromatography (LCA-HPLC) method developed and applied here incorporates a light-chain reaction procedure using a commercially available BoNT/A FRET substrate derived from the SNAP-25 sequence coupled with a reversed-phase (RP)-HPLC analysis procedure to detect and quantitate the fluorescently labeled reaction product(s). The method is unique in that the RP-HPLC analysis eliminates matrix interferences by separating the cleaved substrate products from the non-cleaved substrate, other reaction reagents, and product formulation components, thereby significantly increasing the signal-to-noise ratio. This method provides single-vial sensitivity along with high throughput due to the HPLC automation. Additionally, because the method requires only substrate and no product-specific antibodies or reagents, it provides the opportunity to evaluate and compare drug products; for example assessing the effects of formulation excipients, manufacturing processes, and other parameters on light-chain activity and stability.

Another significant advantage of this procedure is the ability to separate, detect and quantify distinct light-chain cleavage products. While methods exist to measure the light-chain activity of BoNTs [4,5], this is the first method (to our knowledge) to selectively determine, as a routine part of the assay, the actual cleavage product(s) generated by formulated BoNT/A drug products. The adaptable nature of the method also allowed simple substitution of an additional substrate derived from the syntaxin sequence, further extending the range of potential characterization to serotype $\mathrm{C}$ characterization. The straightforward substitution of substrates extends the utility as an identification test [6].

\section{Materials and Methods}

The present study compared the light-chain enzymatic activities of three BoNT/A drug products: onabotulinumtoxinA (BOTOX ${ }^{\circledR}$, Allergan, Inc.; Irvine, CA, USA), incobotulinumtoxinA (Xeomin ${ }^{\circledR}$, Merz Pharmaceuticals; Frankfurt, Germany), and abotulinumtoxinA (Dysport ${ }^{\circledR}$, Ipsen Biopharm Limited; Wrexham, UK). All drug products were stored according to label instructions and tested 
within expiration dating. The light-chain activity and cleavage pattern of these BoNT/A products were assessed using the novel LCA-HPLC method reported here with BoNT/A substrate (SNAPtide ${ }^{\circledR} 520$; List Biological Laboratories, Inc.; Campbell, CA, USA). SNAPtide ${ }^{\circledR} 520$ sequence: Abz Thr D-Arg Ile Asp Gln Ala Asn Gln Arg Ala Thr Lys Nle Lys Dnp; where Abz = o-Aminobenzoic acid (FRET pair fluorophore) and Dnp = 2,4-Dinitrophenyl (FRET pair quencher).

BoNT/A cleavage fragment (designated as SNAPtide ${ }^{\circledR} 529$ by List Biological Laboratories, Inc.) was utilized to identify retention time of the fragment.

900-kD BoNT/A toxin complex (supplied by Allergan, Inc.; Irvine, CA, USA) and 150-kD BoNT/A holotoxin (supplied by Metabiologics, Inc.; Madison, WI, USA) were used to characterize BoNT/A unformulated bulk toxin cleavage.

Commercially available BoNT/C FRET substrate (SYNTAXtide ${ }^{\circledR} 560$; List Biological Laboratories, Inc.; Campbell, CA, USA) was utilized to assess type-C cleavage. Because of the RP-HPLC reaction-product readout, no modification to the method was necessary in order to observe the reaction products generated using the SYNTAXtide ${ }^{\circledR} 560$ substrate.

Trypsin (TrypZean, Sigma-Aldrich Corp.; St. Louis, MO, USA) was utilized to identify characteristic trypsin cleavage while Serotype C light-chain (List Biological Laboratories, Inc.; Campbell, CA, USA) was obtained for type-C cleavage generation.

\subsection{Enzymatic (Light-chain) Reaction Conditions}

Each BoNT/A product vial was reconstituted with $1 \mathrm{~mL}$ of digestion buffer (see Table 2).

Table 2. Reaction solutions.

\begin{tabular}{|c|c|}
\hline Digestion buffer & $0.5 \mathrm{mM} \mathrm{ZnCl}_{2}, 2 \mathrm{mM} \mathrm{DTT}^{\mathrm{a}}, 0.05 \%$ Tween 20 in $50 \mathrm{mM}$ HEPES, pH 7.4 \\
\hline Substrate & $200 \mu \mathrm{M}$ SNAPtide ${ }^{\mathbb{R}} 520^{\mathrm{b}}$ prepared in sterile water for injection \\
\hline
\end{tabular}

A $0.45 \mathrm{~mL}$ aliquot of each reconstituted sample was transferred to separate reaction tubes. The samples were then heated at $37{ }^{\circ} \mathrm{C}$ for 30 minutes (reduction step). After completion of the reduction step, $25 \mu \mathrm{L}$ of $200 \mu \mathrm{M}$ SNAPtide ${ }^{\circledR} 520$ was then added to each tube (equivalent to $10.5 \mu \mathrm{M}$ SNAPtide ${ }^{\circledR} 520$ ). For the experiment using the SYNTAXtide ${ }^{\circledR} 560$ substrate (type-C), a volume of $50 \mu \mathrm{L}$ of $200 \mu \mathrm{M}$ SYNTAXtide ${ }^{\circledR} 560$ was added to each reaction tube (equivalent to $20 \mu \mathrm{M}$ SYNTAXtide $\left.{ }^{\circledR} 560\right)$.

The reaction samples were then incubated at $30{ }^{\circ} \mathrm{C}$ for 20 hours (digestion step). At the completion of the digestion step, $25 \mu \mathrm{L}$ of $5 \%$ trifluoroacetic acid (TFA) was added to each tube to stop the reaction. The contents of each tube were then transferred to HPLC vials for analysis.

\subsection{HPLC Analysis}

The fluorescently labeled cleavage product(s) were separated and detected via an RP-HPLC method using a Waters 2695 XE Separations Module and a Waters 2475 Multi $\lambda$ Fluorescence Detector (see Table 3 for HPLC parameters). 
Table 3. HPLC parameters.

\begin{tabular}{|l|l|}
\hline Column & Waters Symmetry300 ${ }^{\mathrm{TM}} \mathrm{C} 18,3.5 \mu \mathrm{m}, 4.6 \times 150 \mathrm{~mm}(\mathrm{P} / \mathrm{N}: 186000197)$ \\
\hline Column Temperature & $35^{\circ} \mathrm{C}$ \\
\hline Injection Volume & $25 \mu \mathrm{L}$ \\
\hline Flow & $1 \mathrm{~mL} / \mathrm{min}$ \\
\hline Detection & Excitation $\lambda=322 \mathrm{~nm} ;$ Emission $\lambda=420 \mathrm{~nm}$ \\
\hline
\end{tabular}

The samples were eluted using a gradient program (see Table 4) with a mobile phase consisting of $0.1 \%$ TFA in water (A) and $0.1 \%$ TFA in acetonitrile (B). The data were collected and analyzed via Waters EmpowerTM Pro software (Waters Corp.; Milford, MA, USA).

Table 4. HPLC Gradient Program.

\begin{tabular}{|c|c|c|}
\hline Time (min) & \%A & \%B \\
\hline 0 & 90 & 10 \\
\hline 5 & 90 & 10 \\
\hline 13 & 85 & 15 \\
\hline 18 & 5 & 95 \\
\hline 20 & 5 & 95 \\
\hline 21 & 90 & 10 \\
\hline 30 & 90 & 10 \\
\hline
\end{tabular}

\section{Results and Discussion}

The LCA-HPLC method demonstrated excellent single-vial sensitivity and resolution of the fluorescently labeled BoNT/A cleavage fragment (designated as SNAPtide ${ }^{\circledR} 529$ by List Biological Laboratories, Inc.) when analyzing onabotulinumtoxinA, abotulinumtoxinA and incobotulinumtoxinA drug products. See Figure 1 for an example chromatogram of onabotulinumtoxinA. No formulation or reaction component interferences were observed.

Figure 1. Chromatogram of onabotulinumtoxinA (BOTOX ${ }^{\circledR}$ Lot $\# \mathrm{C} 1550 \mathrm{C} 1$ ) reaction solution (SNAPtide ${ }^{\circledR} 520$ substrate) exemplifying generation of the 529 fragment peak.

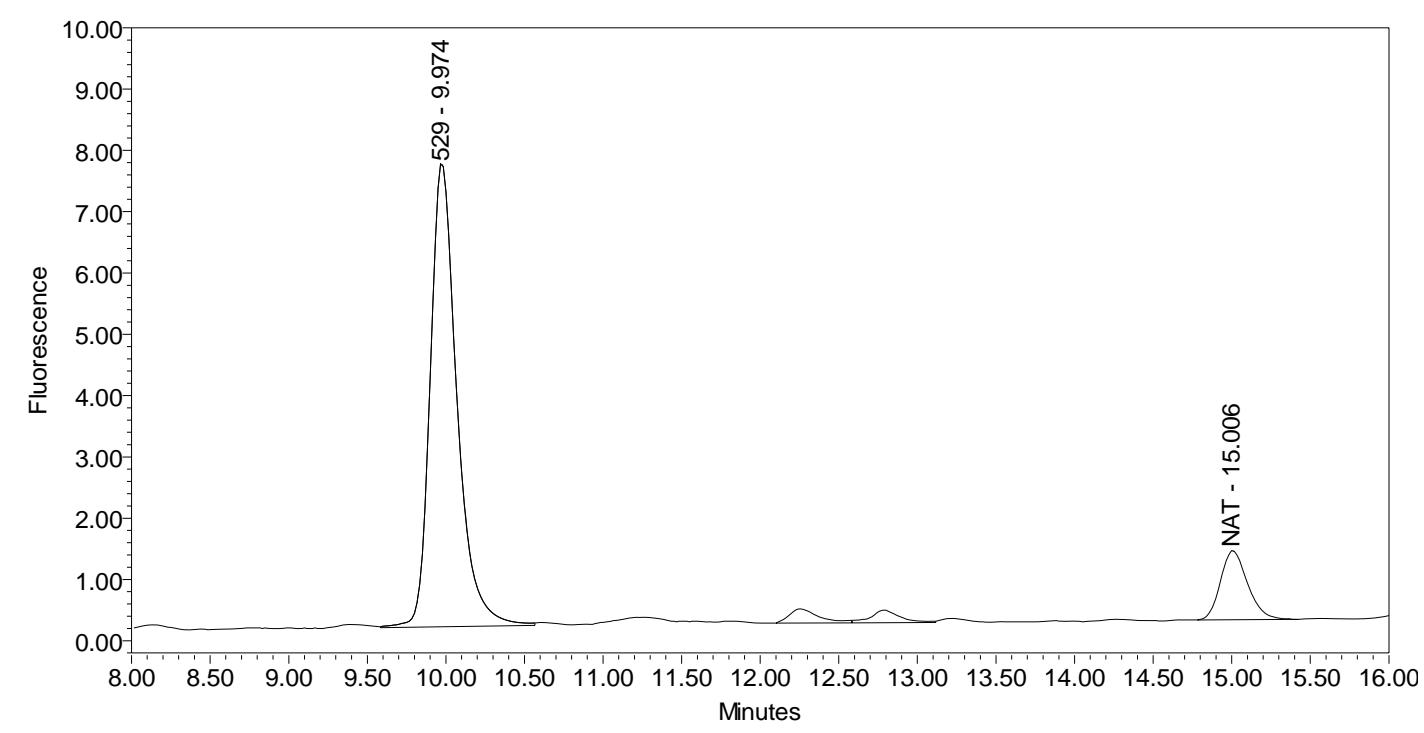


An excipient peak, identified as $N$-Acetyl-tryptophan (NAT), exists in all the commercial product chromatograms but is readily resolved from the reaction products. NAT is used as a stabilizer in human serum albumin (HSA). OnabotulinumtoxinA, abotulinumtoxinA, and incobotulinumtoxinA drug products all contain HSA.

All BoNT/A drug products tested generated the expected BoNT/A substrate cleavage product. However, when analyzed using the LCA-HPLC method, the incobotulinumtoxinA drug product generated two (2) substrate cleavage products (see Figure 2).

Figure 2. Chromatogram of incobotulinumtoxinA $\left(\mathrm{Xeomin}^{\circledR}\right.$ Lot \#408012) reaction solution (SNAPtide ${ }^{\circledR} 520$ Substrate) exemplifying generation of the 529 fragment peak and the atypical "T fragment" peak.

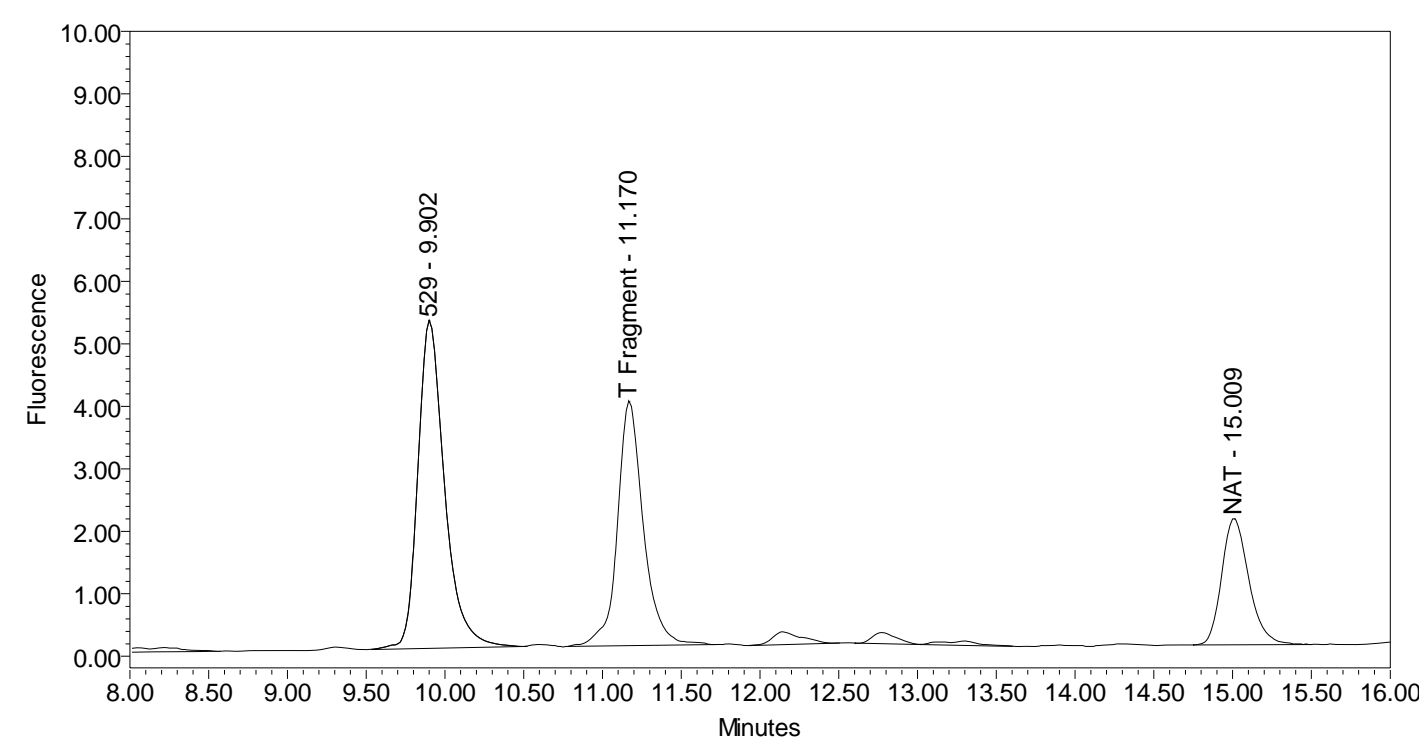

Under identical reaction conditions, onabotulinumtoxinA generated only the expected BoNT/A substrate cleavage product (see Figure 1), as did abotulinumtoxinA (see Figure 3).

Figure 3. Chromatogram of abotulinumtoxinA (Dysport $^{\circledR}$ Lot \#589AB) reaction solution (SNAPtide ${ }^{\circledR} 520$ Substrate) exemplifying generation of the 529 fragment peak.

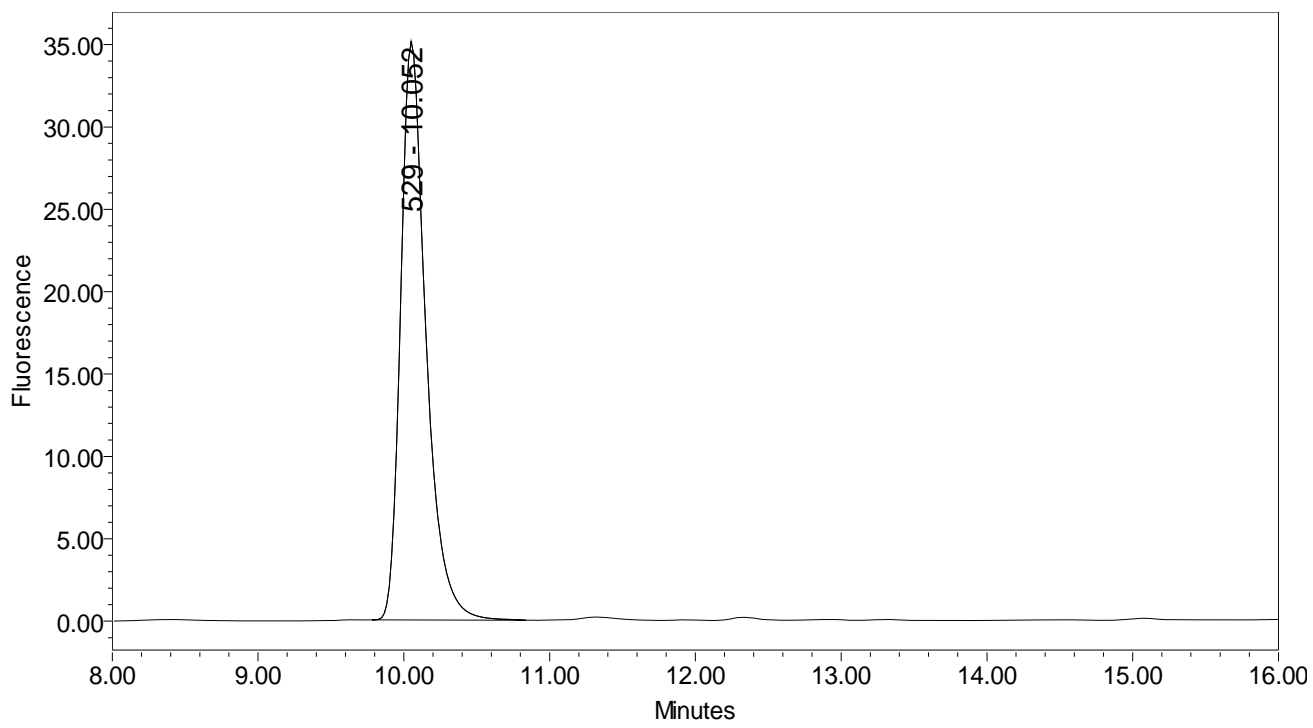


In addition, samples of bulk $150-\mathrm{kD}$ BoNT/A and $900-\mathrm{kD}$ BoNT/A only generated the single expected BoNT/A substrate cleavage product [7](see Figures 4 and 5).

Figure 4. Chromatogram of $150-\mathrm{kD}$ BoNT/A reaction solution (SNAPtide ${ }^{\circledR} 520$ Substrate) exemplifying generation of the 529 fragment peak.

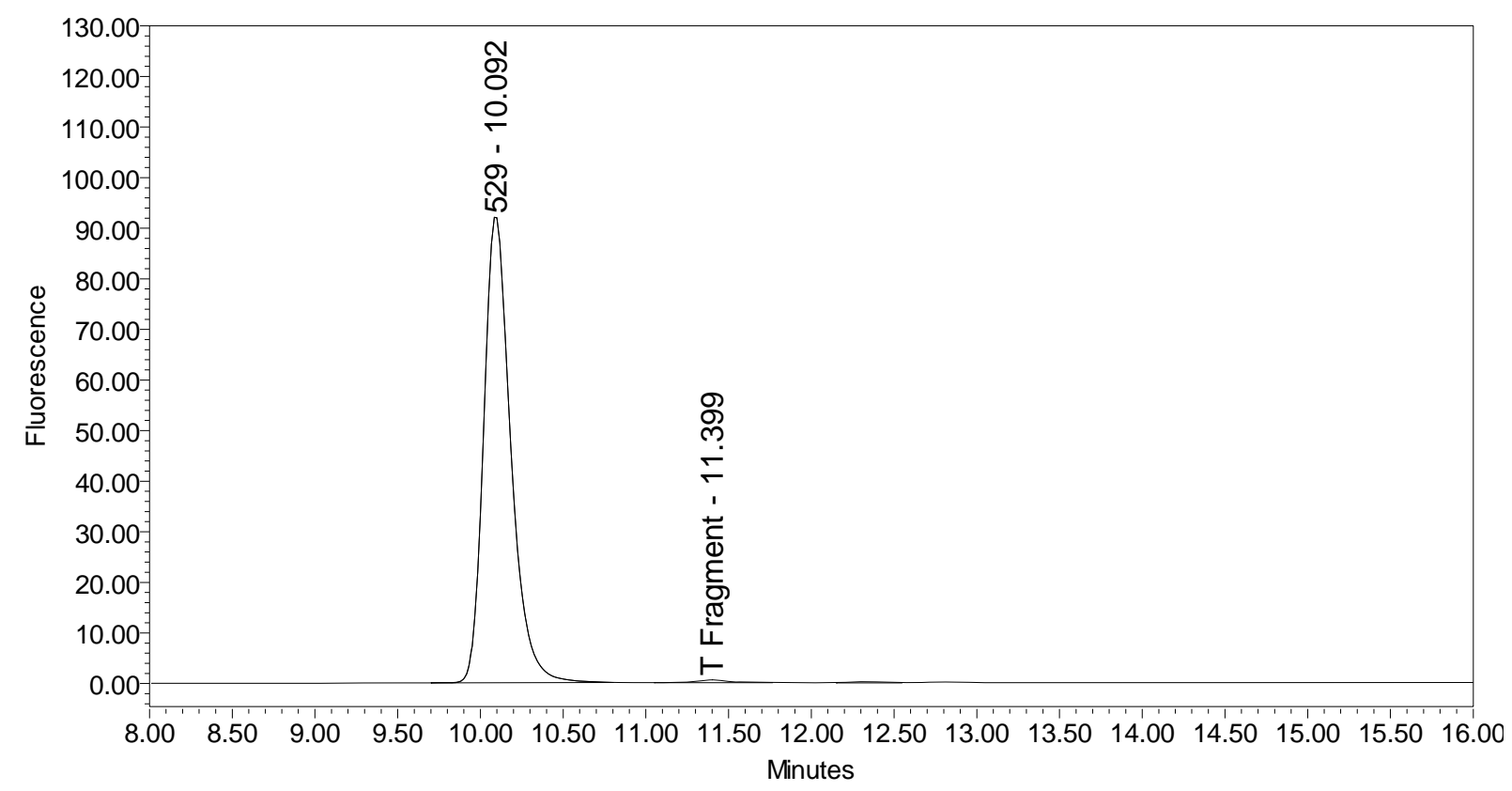

Figure 5. Chromatogram of $900-\mathrm{kD}$ BoNT/A reaction solution (SNAPtide ${ }^{\circledR} 520$ substrate) exemplifying generation of the 529 fragment peak.

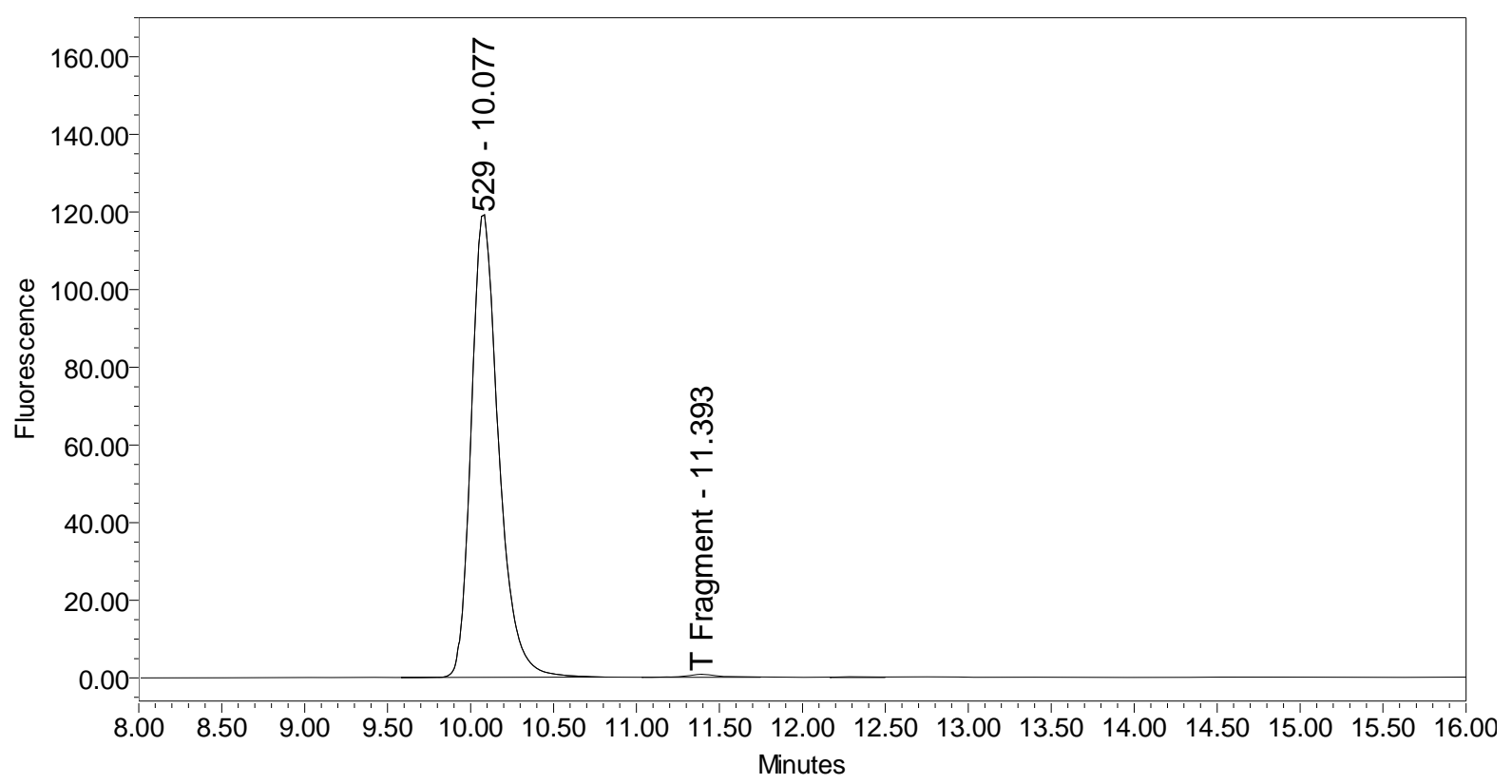

The secondary cleavage product observed from incobotulinumtoxinA was identified by HPLC retention time as the SNAPtide ${ }^{\circledR} 529$ fragment plus one amino acid (see Figures 6 and 7). 
Figure 6. Chromatogram of synthesized samples of SNAPtide ${ }^{\circledR} 529$ and "T fragment" for retention time identification. Elution positions match the generated cleavage fragments.

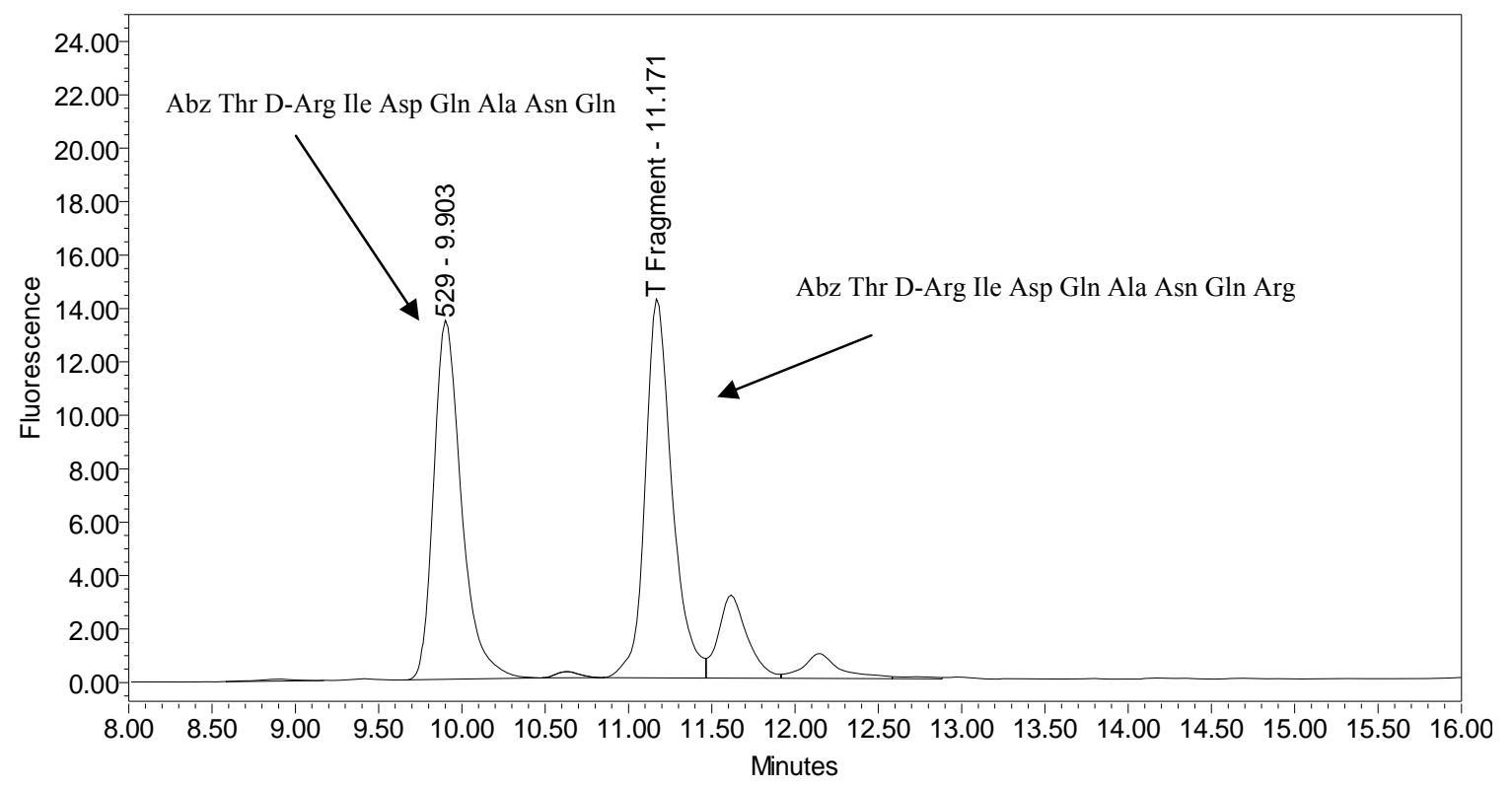

Figure 7. BoNT/A Reaction Scheme with SNAPtide ${ }^{\circledR} 520$ Substrate.

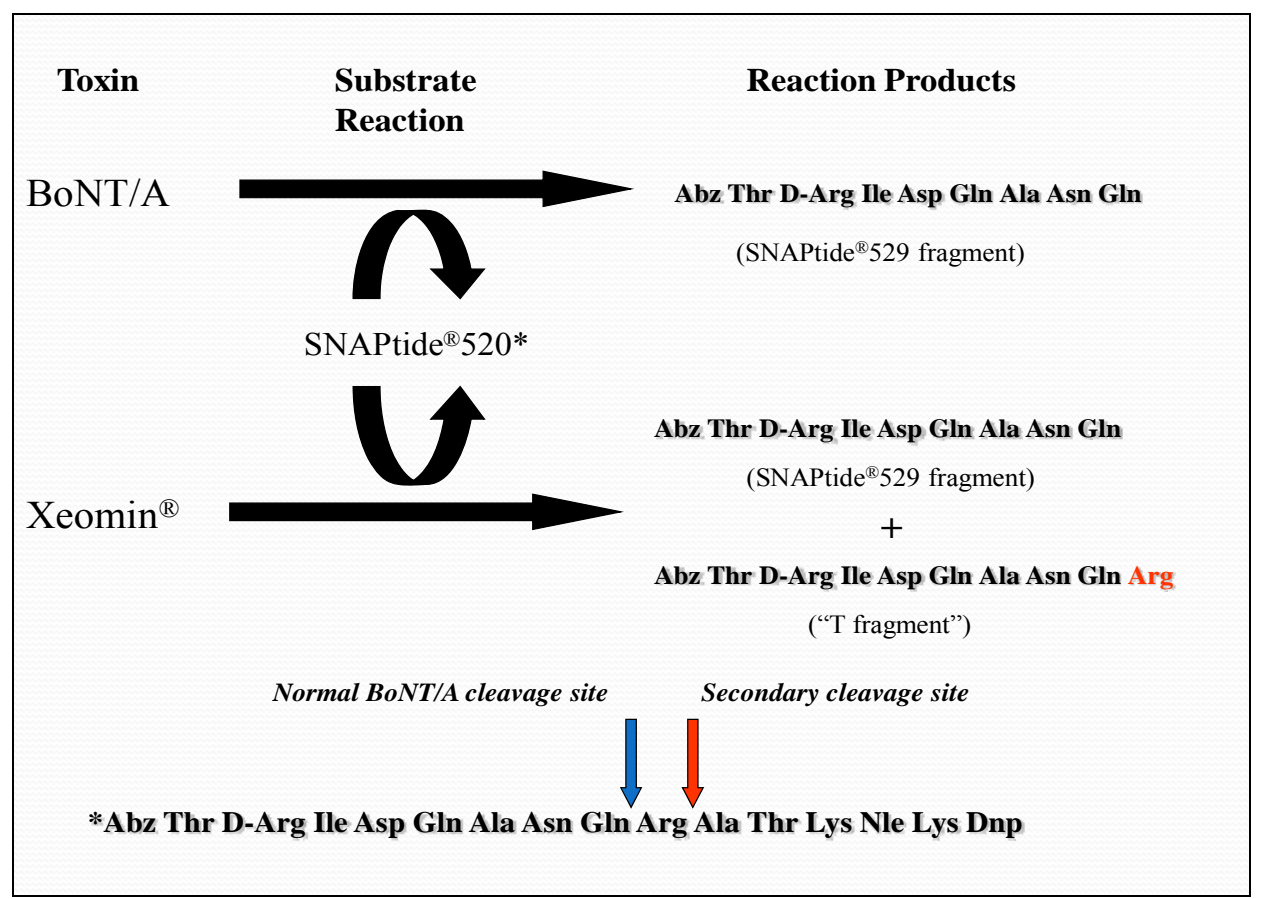

This was accomplished by injecting a range of synthesized SNAPtide ${ }^{\circledR} 520$ fragments along with the SNAPtide ${ }^{\circledR} 529$ fragment and comparing the retention times. The sequence for the SNAPtide ${ }^{\circledR} 520$ substrate is given in the List Biological Laboratories, Inc., patent [8]. BoNT/A specifically cleaves SNAP-25 1-206 at position Gln197-Arg198, while the secondary cleavage product is the result of

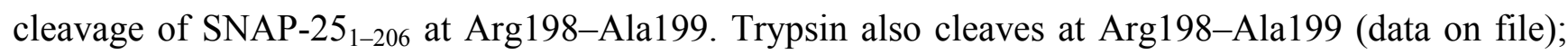
hence, this secondary cleavage product observed from incobotulinumtoxinA was termed the "T fragment" for convenience. It should be noted that this is also the cleavage site for serotype $\mathrm{C}$ toxin (BoNT/C)[9]. 
A control reaction was run on the incobotulinumtoxinA product, without the SNAPtide ${ }^{\circledR} 520$ substrate, to elucidate whether the observed peak was indeed due to the cleavage of the substrate or whether it was an extraneous peak due to the formulation ingredients or to a formulation matrix interaction with a reaction component (see Figure 8).

Figure 8. Chromatogram of incobotulinumtoxinA (Xeomin ${ }^{\circledR}$ Lot \#408012) reaction solution without the addition of substrate demonstrating drug product generates no peaks in the absence of substrate.

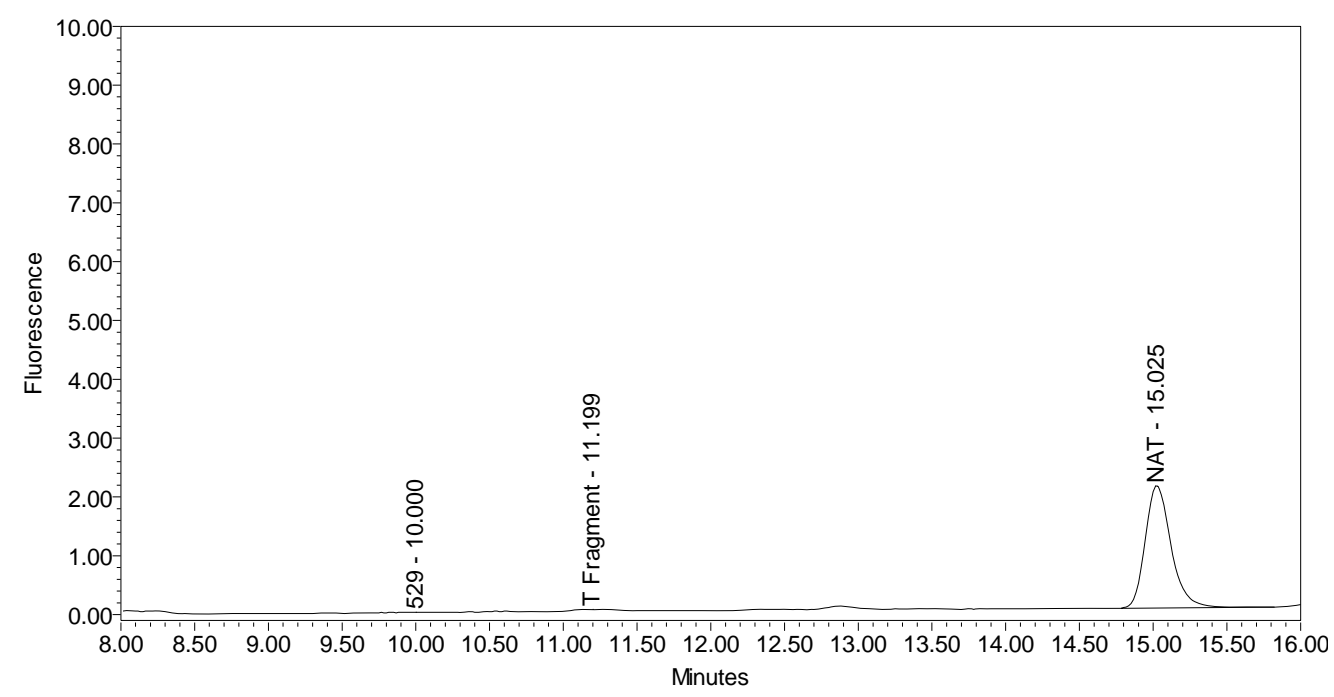

No peak eluting at the retention time of the "T fragment" peak was observed in this control reaction, confirming that the "T fragment" peak generated by incobotulinumtoxinA was indeed due to enzymatic cleavage of SNAPtide ${ }^{\circledR} 520$ substrate.

Peak area results for five incobotulinumtoxinA drug product lots along with a onabotulinumtoxinA drug product lot are given in Figure 9. All incobotulinumtoxinA drug products assayed demonstrated significant levels of secondary cleavage.

Figure 9. Peak area results for incobotulinumtoxinA (Xeomin $\left.{ }^{\circledR}\right)$ samples compared to onabotulinumtoxinA $\left(\right.$ BOTOX $\left.^{\circledR}\right)$ control. Samples analyzed by LCA-HPLC using the SNAPtide ${ }^{\circledR} 520$ substrate. Test Date: April 2007, all samples tested within expiry.

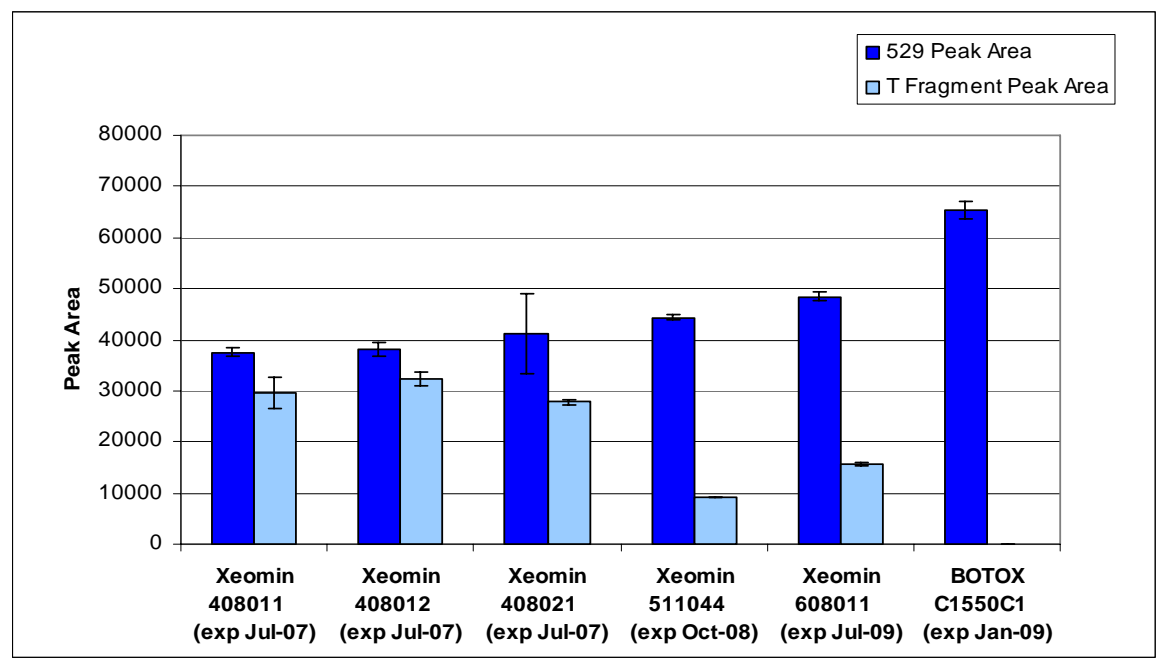


When onabotulinumtoxinA drug product was analyzed without reduction, i.e., DTT omitted from the reaction buffer, no substantial reaction products were observed (see Figure 10).

Figure 10. Chromatogram of onabotulinumtoxin $A\left(B O T O X^{\circledR}\right.$ Lot $\left.\# \mathrm{C} 1550 \mathrm{C} 1\right)$ reaction solution without the reduction step (no DTT added) demonstrating the 529 peak is not generated from by onabotulinumtoxinA from the SNAPtide ${ }^{\circledR} 520$ substrate without reduction.

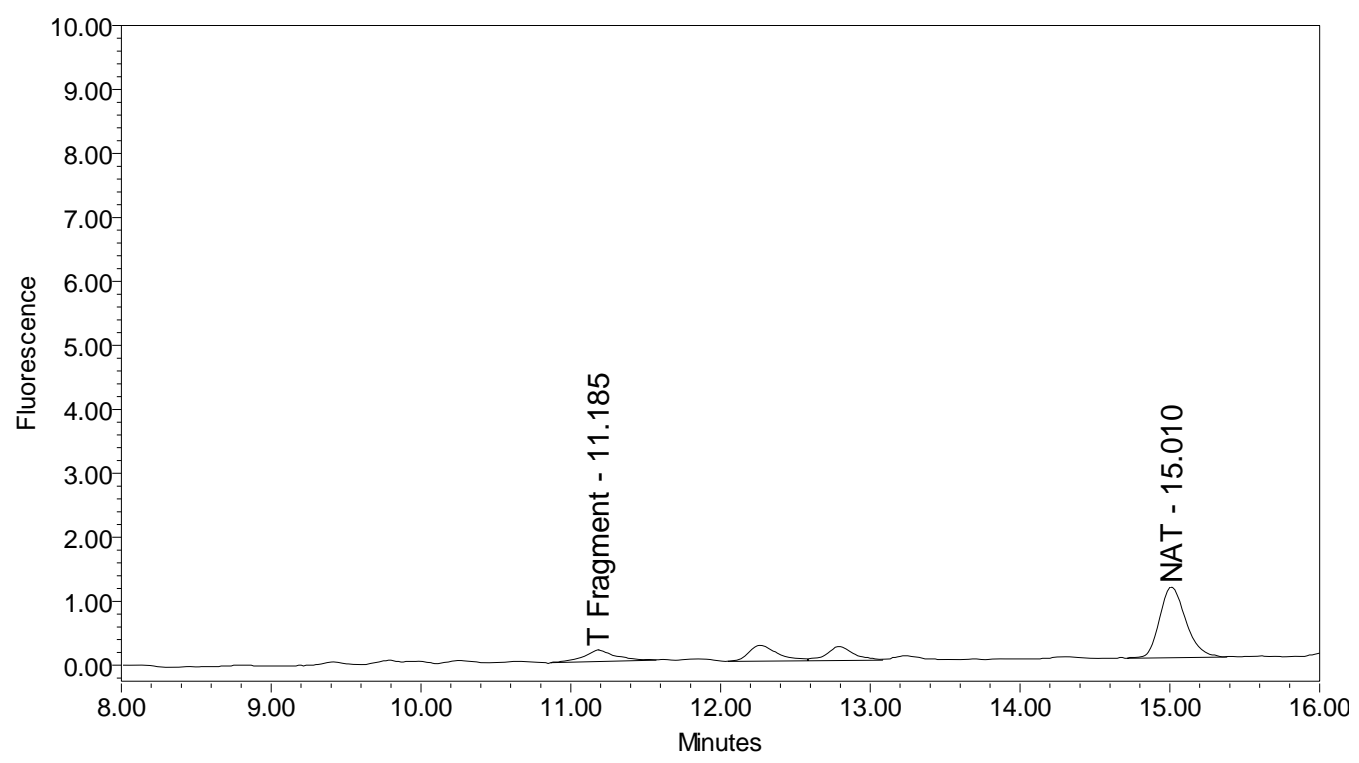

However, when incobotulinumtoxinA drug product was analyzed without the reduction step (no DTT), the secondary cleavage product ("T fragment") was still generated (see Figure 11), indicating reduction is not necessary for this cleavage. No SNAPtide ${ }^{\circledR} 529$ fragment (primary BoNT/A cleavage product) was detected when testing incobotulinumtoxinA drug product under non-reduced conditions.

Figure 11. Chromatogram of incobotulinumtoxinA (Xeomin ${ }^{\circledR}$ Lot \#408012) reaction solution without the reduction step (no DTT added) exemplifying the "T fragment" peak is generated by incobotulinumtoxinA from the SNAPtide ${ }^{\circledR} 520$ substrate without reduction.

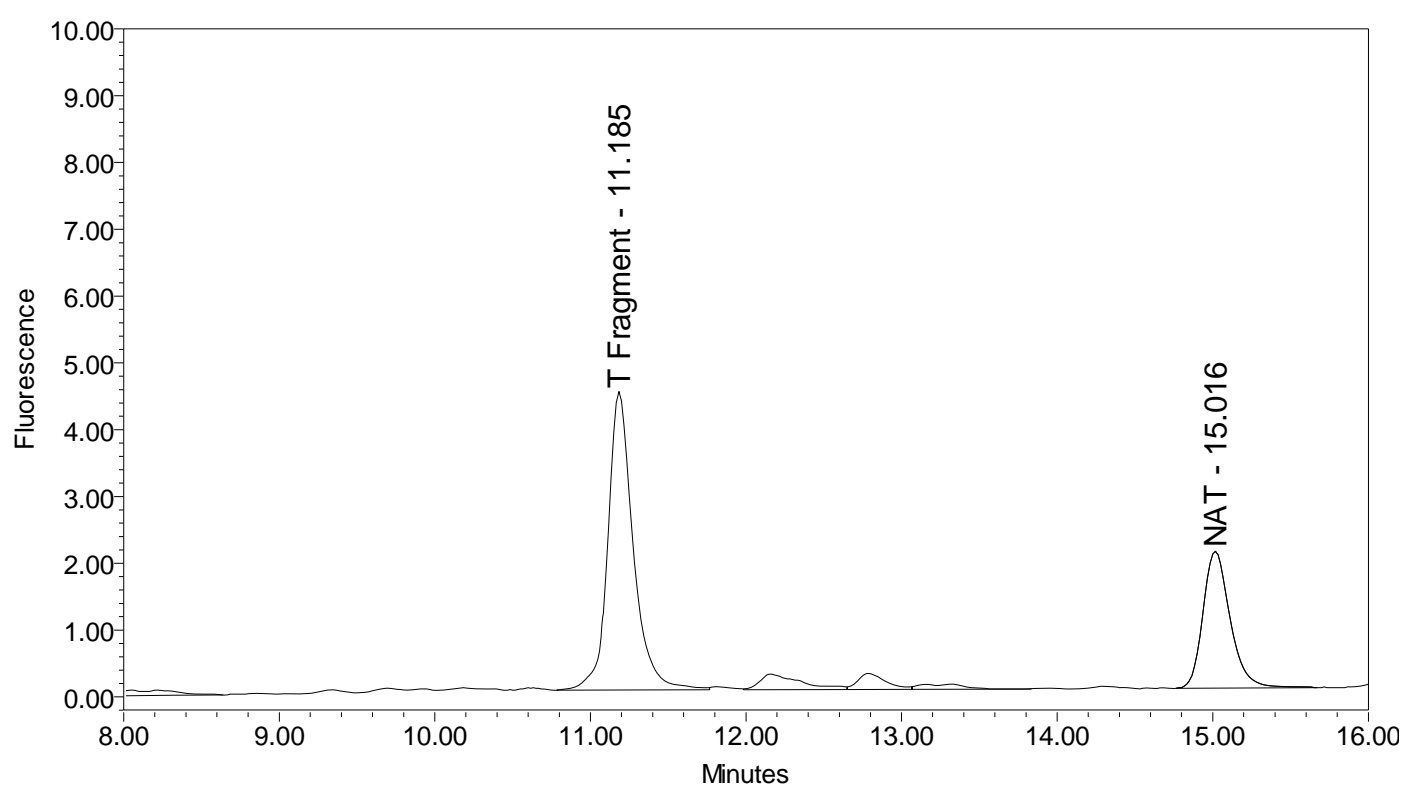


When reacted with the SYNTAXtide ${ }^{\circledR} 560$ substrate (serotype C substrate), incobotulinumtoxinA drug product generated a major peak eluting at 3.5 minutes along with two (2) small peaks eluting at 10.3 and 15.7 minutes, respectively (see Figure 12).

Figure 12. Chromatogram of incobotulinumtoxin $A$ (Xeomin ${ }^{\circledR}$ Lot \#708041) reaction solution with SYNTAXtide ${ }^{\circledR} 560$ substrate (serotype C substrate) demonstrating the incobotulinumtoxinA BoNT/A drug product cleaves serotype C substrate.

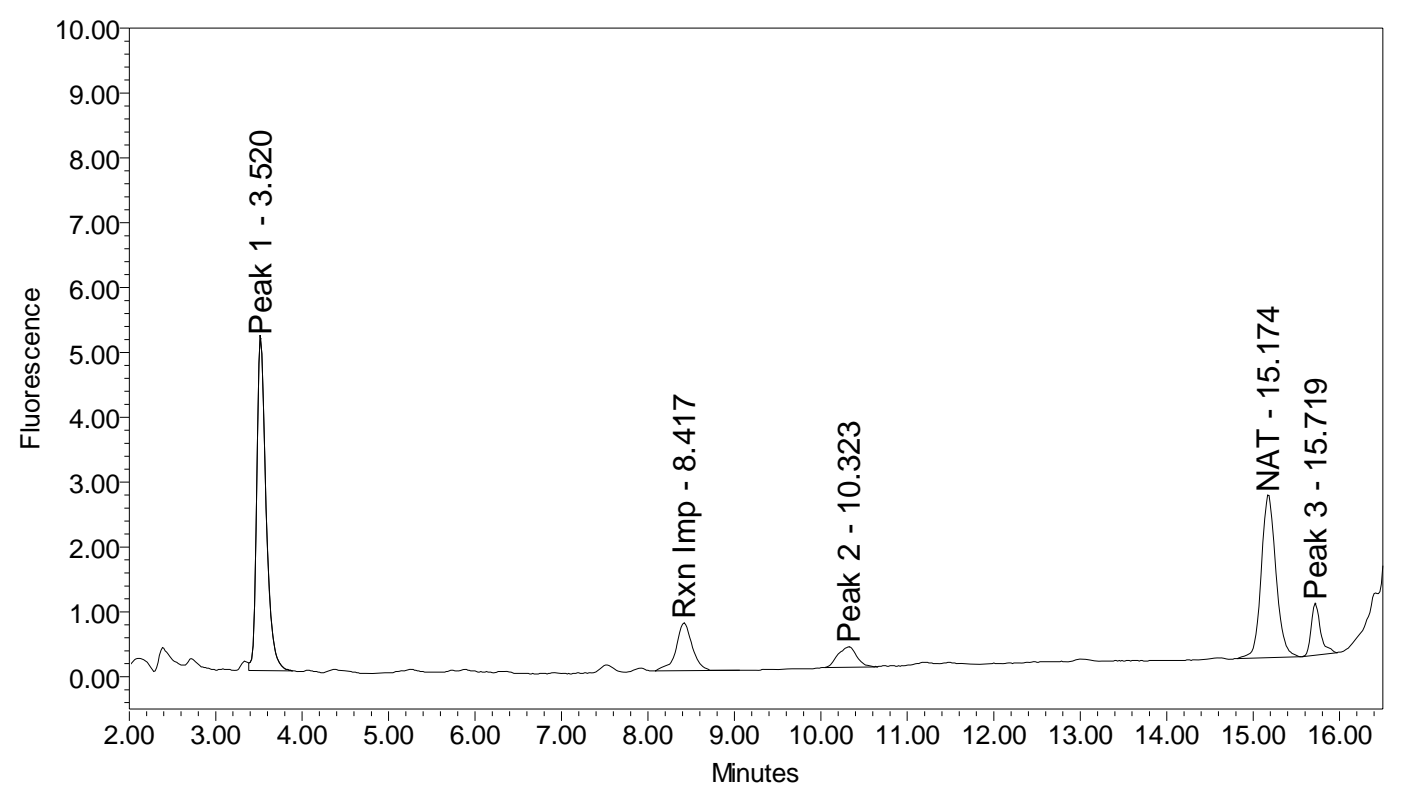

Neither onabotulinumtoxinA or abotulinumtoxinA generated any cleavage products when reacted with the SYNTAXtide ${ }^{\circledR} 560$ substrate (see Figures 13 and 14).

Figure 13. Chromatogram of onabotulinumtoxinA (BOTOX® Lot \#408012) reaction solution with SYNTAXtide ${ }^{\circledR} 560$ substrate (serotype $C$ substrate) exemplifying the onabotulinumtoxinA BoNT/A drug product does not cleave serotype $\mathrm{C}$ substrate.

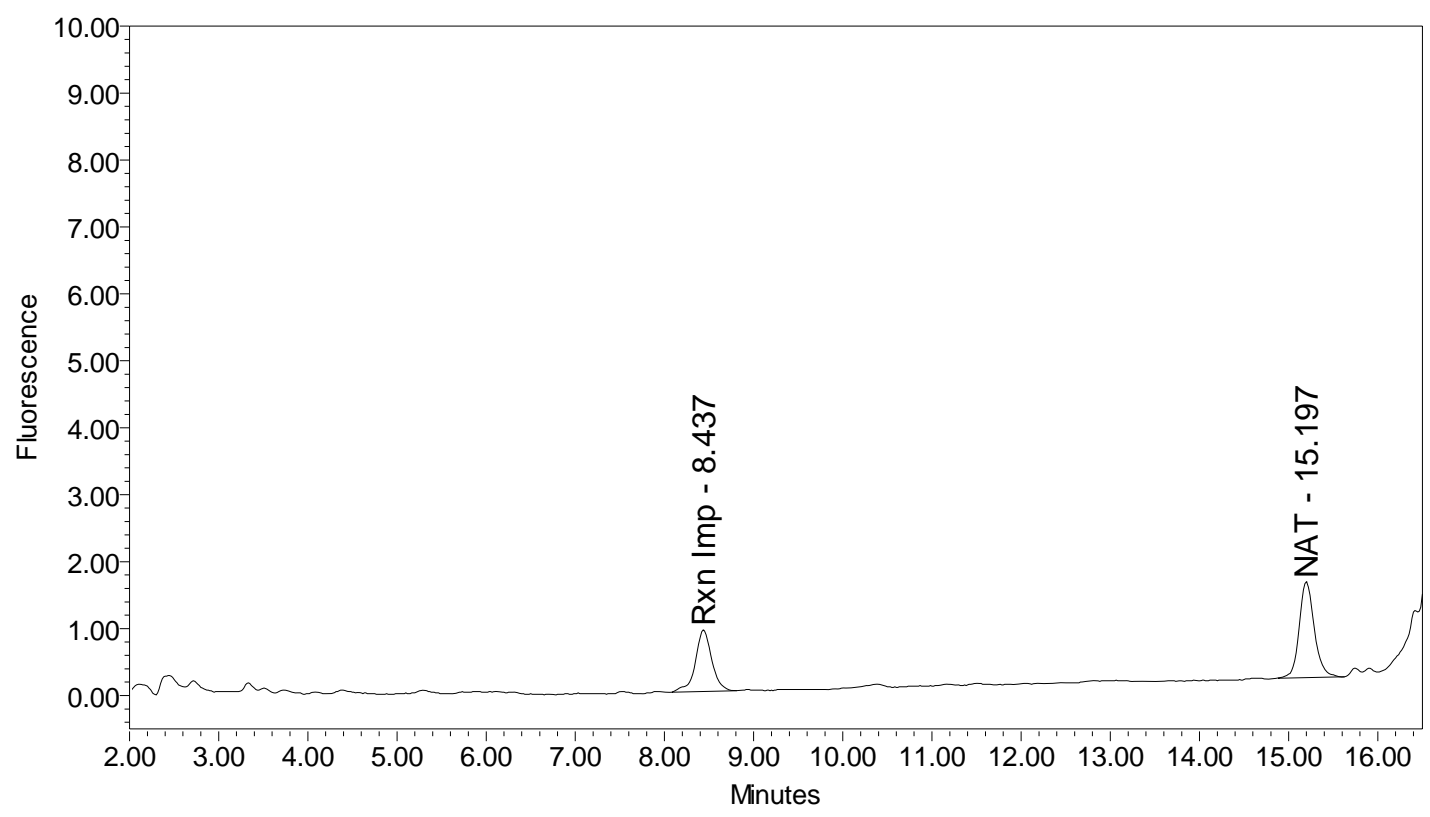


Figure 14. Chromatogram of abotulinumtoxinA (Dysport ${ }^{\circledR}$ Lot $\# 710 A$ ) reaction solution with SYNTAXtide ${ }^{\circledR} 560$ substrate (serotype C substrate) exemplifying the abotulinumtoxinA BoNT/A drug product does not cleave serotype $\mathrm{C}$ substrate.

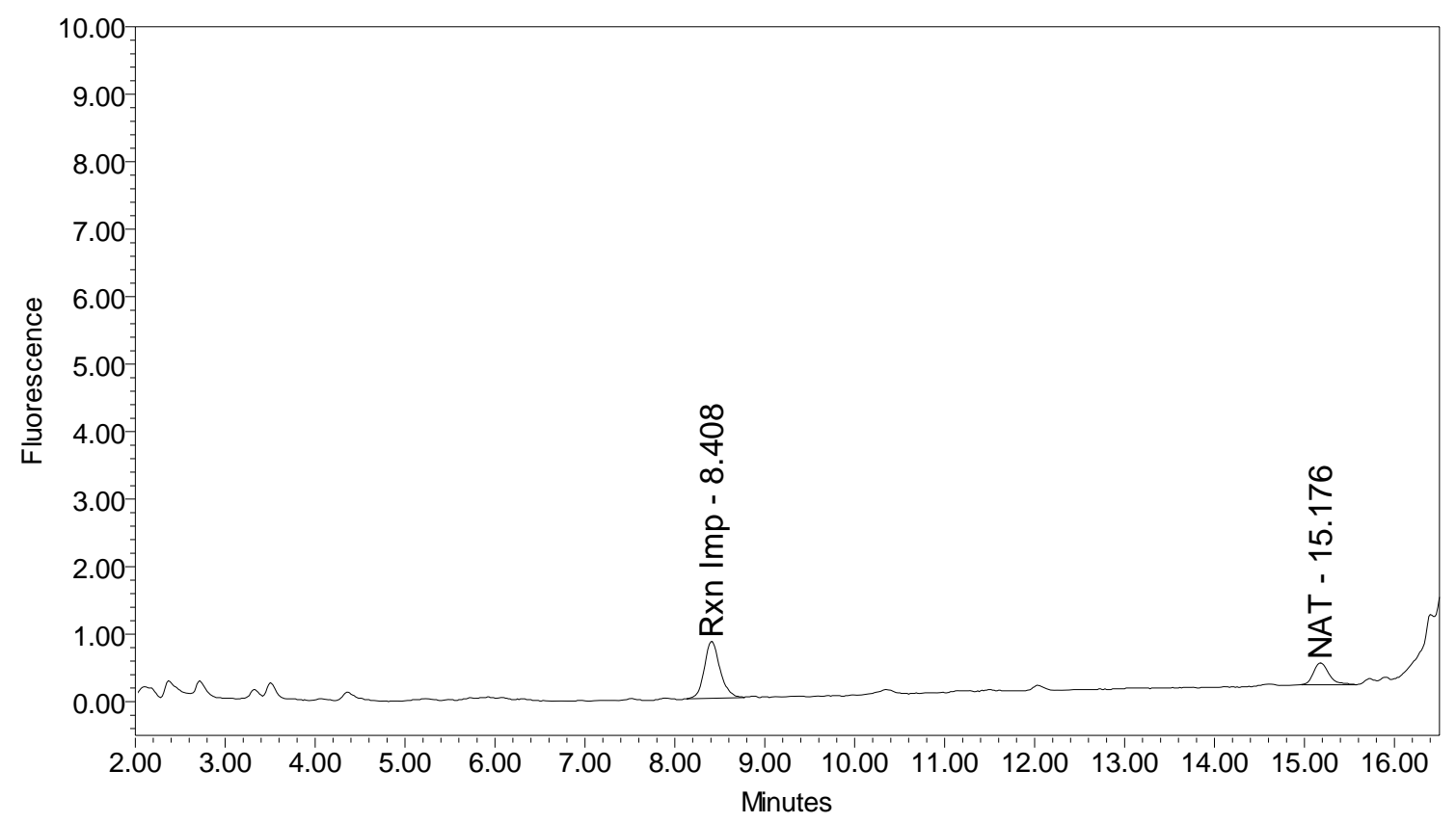

Trypsin also produced three (3) reaction products that corresponded to the retention times of the incobotulinumtoxinA reaction products, however at different ratios (see Figure 15).

Figure 15. Chromatogram of trypsin reaction solution with SYNTAXtide ${ }^{\circledR} 560$ substrate (serotype $\mathrm{C}$ substrate) demonstrating trypsin cleavage pattern for serotype $\mathrm{C}$ substrate.

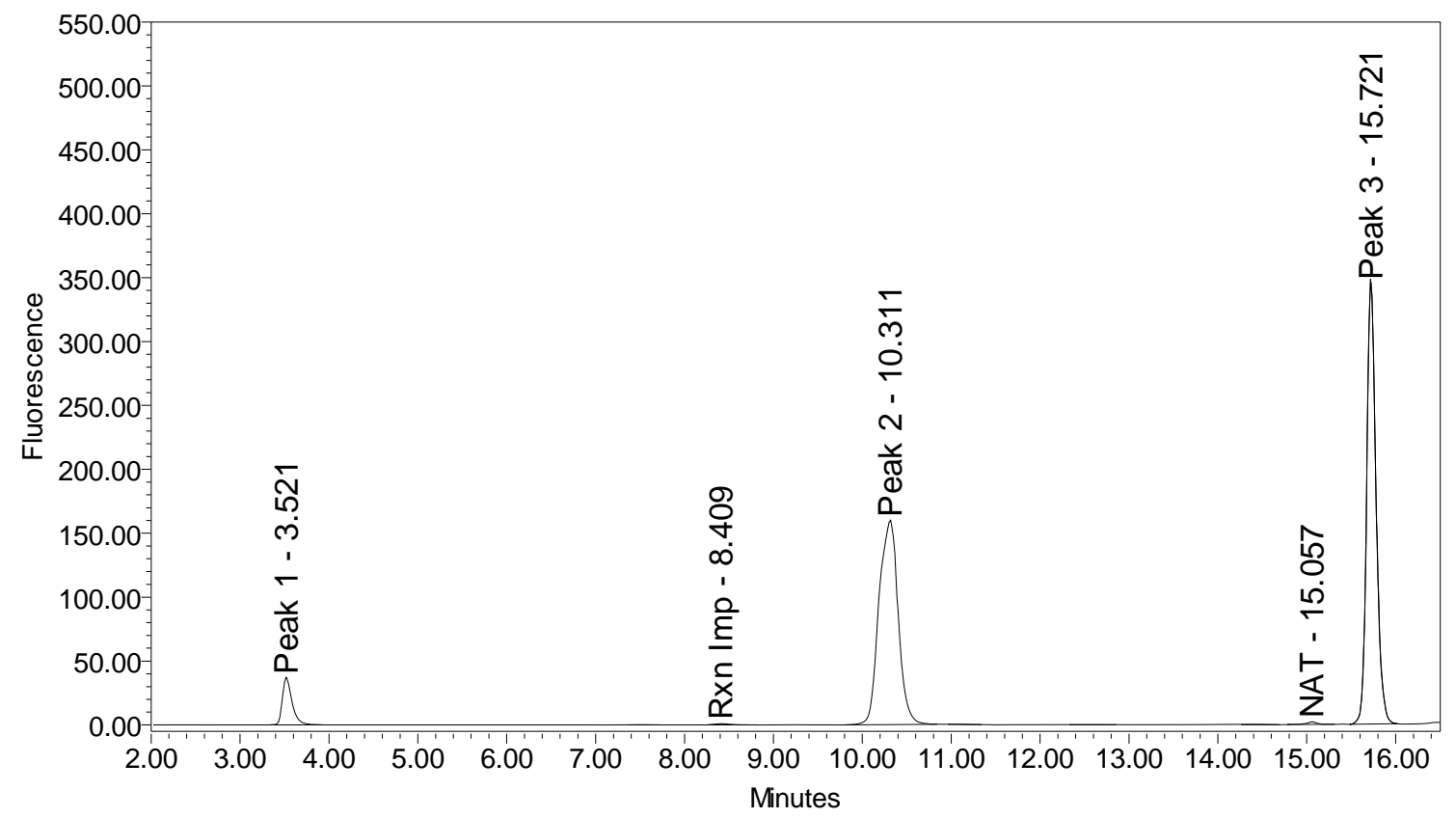

For trypsin, the peaks eluting at 10.3 and 15.7 minutes were the largest, with a smaller peak at eluting 3.5 minutes. Serotype C light-chain generated a single peak eluting at 10.4 minutes (see Figure 16). 
Figure 16. Chromatogram of serotype $\mathrm{C}$ light-chain reaction solution with SYNTAXtide ${ }^{\circledR} 560$ substrate (serotype C substrate) demonstrating typical serotype C cleavage pattern against serotype $\mathrm{C}$ substrate.

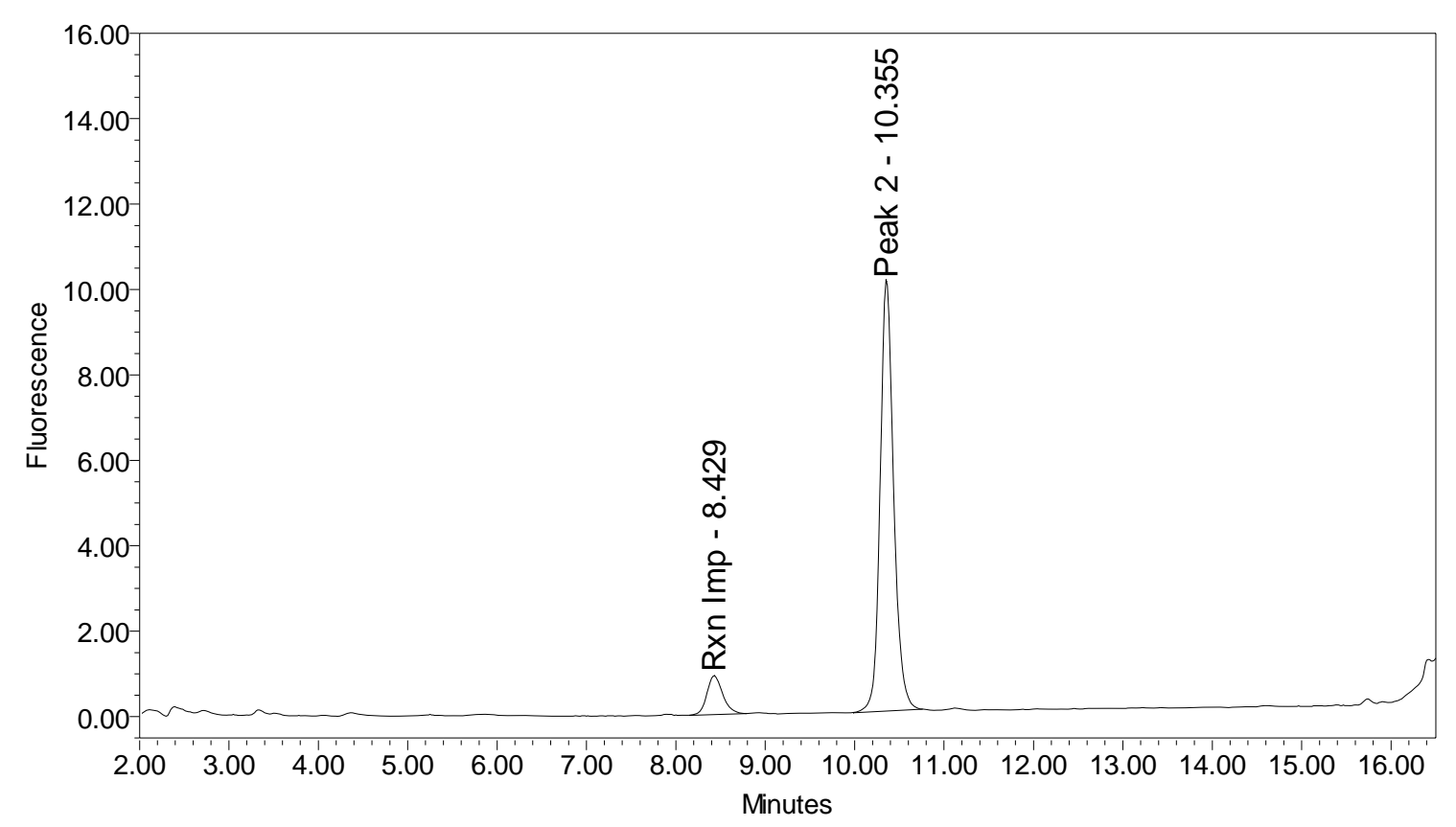

A summary of the cleavage patterns observed using the SYNTAXtide ${ }^{\circledR} 560$ substrate is given in Table 5. It should be noted that the peak eluting at 8.5 minutes observed in all the chromatograms (labeled as reaction impurity) is from an impurity in one of the reaction components.

Table 5. Summary of cleavage products observed with SYNTAXtide ${ }^{\circledR} 560$ substrate (serotype $\mathrm{C}$ substrate) for drug products and control enzymes.

\begin{tabular}{|l|c|c|c|}
\hline \multirow{2}{*}{} & \multicolumn{3}{|c|}{ Retention Time } \\
\cline { 2 - 4 } & $\mathbf{3 . 5}$ minutes & $\mathbf{1 0 . 3}$ minutes & 15.7 minutes \\
\hline onabotulinumtoxinA & Non-detected & Non-detected & Non-detected \\
\hline abotulinumtoxinA & Non-detected & Non-detected & Non-detected \\
\hline incobotulinumtoxinA & Major peak & Minor peak & Minor peak \\
\hline Serotype C light-chain & Non-detected & Major peak & Non-detected \\
\hline Trypsin & Minor peak & Major peak & Major peak \\
\hline
\end{tabular}

\section{Conclusions}

The suitability of the method was exemplified through analysis of three distinct BoNT/A drug products. The method was shown to be robust and sensitive as applied to single vials of drug products with very different formulations. Light-chain activity ranked abotulinumtoxinA $>$ onabotulinumtoxinA $>$ incobotulinumtoxinA. It should be noted that the abotulinumtoxinA product label stated potency as $500 \mathrm{U}$, so it was not surprising that it produced more enzymatic activity, whereas the incobotulinumtoxinA label claims $100 \mathrm{U}$, although it consistently assayed significantly lower than the other $100 \mathrm{U}$ product (onabotulinumtoxinA). 
IncobotulinumtoxinA drug product generated a secondary SNAP cleavage product not produced at significant levels by any other BoNT/A drug product or BoNT/A bulk toxin tested. Possible explanations include damaged BoNT/A or a contaminating protease that cleaves SNAPtide ${ }^{\circledR} 520$ substrate at the $C$-terminal end of arginine (corresponding to SNAP-25 Arg198-Ala199). Based on the cleavage site, suspected candidates for a contaminating protease could include endogenous cell-derived trypsin-like protease or toxin co-expression during fermentation (serotype $\mathrm{C}$ and $\mathrm{A}$ behavior). We eliminated co-expression of serotype $\mathrm{C}$ as a plausible explanation because while serotype C light-chain cleaves SYNTAXtide ${ }^{\circledR} 560$ it does not cleave SNAPtide ${ }^{\circledR} 520$ (supplier information verified by data on file) and therefore would not produce the $\mathrm{T}$ fragment. Another explanation is that the type-A holotoxin is damaged during processing and/or degraded during storage, thereby altering its proteolytic behavior [10]. To our knowledge, this is the first reported observation of this unusual behavior related to a BoNT/A toxin. In addition, older lots of incobotulinumtoxinA consistently exhibited lower light-chain activity (type-A cleavage) when compared to newer lots, combined with an increase in the ratio of secondary substrate cleavage product to primary cleavage product (see Figure 9); suggesting the incobotulinumtoxinA drug product may be degrading during storage.

While the origin and nature of the secondary substrate cleavage produced by incobotulinumtoxinA is unknown, a difference in the proteolytic mechanism was elucidated by this study. This difference was observed when drug product samples were analyzed without reduction with DTT. In order for BoNT/A light-chain activity to occur, the disulfide link between the $100-\mathrm{kD}$ heavy-chain and the $50-\mathrm{kD}$ light-chain must be reduced. As expected, no BoNT/A cleavage product (SNAPtide ${ }^{\circledR} 529$ ) was observed without reduction in any samples. However incobotulinumtoxinA samples generated the secondary fragment in the absence of a reduction step, consistent with a different proteolytic mechanism. In any event it seems evident that some enzymatic activity is directed to the secondary mechanism and may also be contributing to loss during storage; e.g., a degrative contaminant protease.

In an expanded experiment, incobotulinumtoxinA demonstrated cleavage of a BoNT/C substrate that was not observed in the other BoNT/A drug products tested. The cleavage pattern of the BoNT/C substrate by incobotulinumtoxinA was inconsistent with that of trypsin and BoNT/C light-chain. It is interesting to note that this is the only drug product utilizing the naked $150-\mathrm{kD}$ holotoxin. A comprehensive understanding of BoNT/A drug product differentiation would benefit from additional investigation into this phenomenon now that a tool exists to detect and measure it.

\section{References}

1. Oguma, K.; Fujinaga, Y.; Inoue, K. Structure and Function of Clostridium botulinum Toxins. Microbiol. Immunol. 1995, 39, 161-168.

2. Vaidyanathan, V.V.; Yoshino, K.; Jahnz, M.; Dorries, C.; Bade, S.; Nauenburg, S.; Niemann, H.; Binz, T. Proteolysis of SNAP-25 Isoforms by Botulinum Neurotoxin Types A, C, and E: Domains and Amino Acid Residues Controlling the Formation of Enzyme-Substrate Complexes and Cleavage. J. Neurochem. 1999, 72, 327-337.

3. Jones, R.G.A.; Liu, Y.; Sesardic, D. New Highly Specific Botulinum Type C1 Endopeptidase Immunoassays Utilising SNAP25 or Syntaxin Substrates. J. Immunol. Methods 2009, 343, 21-27. 
4. Schmidt, J.J.; Stafford, R.G.; Millard, C.B. High-Throughput Assays for Botulinum Neurotoxin Proteolytic Activity: Serotypes A, B, D, and F. Anal. Biochem. 2001, 296, 130-137.

5. Rasooly, R.; Do, P.M. Development of an in Vitro Activity Assay as an Alternative to the Mouse Bioassay for Clostridium botulinum Neurotoxin Type A. Appl. Environ. Microbiol. 2008, 74, 4309-4313.

6. Hunt, T.; Clarke, K. Potency of the botulinum toxin product CNBTX-A significantly exceeds labelled units in standard potency test. J. Am. Acad. Dermatol. 2008, 58, 517-518.

7. Shimizu, G.; Rupp, D.; Tam, K.; Aoki, K.R.; Hunt, T. Characterization of Time-Dependent Enzymatic Profiles Under Various Liquid Conditions for 150 and $900 \mathrm{kDa}$ Botulinum Type-A Neurotoxins. Toxicon 2008, 51 (suppl.), 21.

8. Shine, N.R.; Crawford, K.R.; Eaton, L.J.A. Substrate Peptides and Assays for Detecting and Measuring Proteolytic Activity of Serotype A Neurotoxin From Clostridium botulinum. U.S. Patent 6,504,006, 7 January 2003.

9. Humeau, Y.; Doussau, F.; Grant, N.; Poulain, B. How Botulinum and Tetanus Neurotoxins Block Neurotransmitter Release. Biochimie 2000, 82, 427-446.

10. Hunt, T.; Clarke, K. Potency evaluation of a Formulated Drug Product Containing 150-kD Botulinum Neurotoxin Type A. Clin. Neuropharmacol. 2009, 32 (1), 28-31.

(C) 2010 by the authors; licensee MDPI, Basel, Switzerland. This article is an Open Access article distributed under the terms and conditions of the Creative Commons Attribution license (http://creativecommons.org/licenses/by/3.0/). 